\title{
CORRECTION
}

View Article Online

View Journal I View Issue

\section{Correction: Miscibility studies of two twist-bend nematic liquid crystal dimers with different average molecular curvatures. A comparison between experimental data and predictions of a Landau mean-field theory for the $\mathrm{N}_{\mathrm{TB}}-\mathrm{N}$ phase transition}

Cite this: Phys. Chem. Chem. Phys., 2016, 18, 6955

D. O. López, ${ }^{\star a}$ B. Robles-Hernández, ${ }^{a b}$ J. Salud, ${ }^{a}$ M. R. de la Fuente, ${ }^{b}$ N. Sebastián, ${ }^{c}$ S. Diez-Berart, ${ }^{a}$ X. Jaen, ${ }^{a}$ D. A. Dunmur ${ }^{d}$ and G. R. Luckhurst ${ }^{e}$

DOI: $10.1039 /$ c6cp90042a

Correction for 'Miscibility studies of two twist-bend nematic liquid crystal dimers with different average molecular curvatures. A comparison between experimental data and predictions of a Landau mean-field www.rsc.org/pccp theory for the $\mathrm{N}_{\mathrm{TB}}-\mathrm{N}$ phase transition' by D. O. López et al., Phys. Chem. Chem. Phys., 2016, 18, 4394-4404.

Eqn (25)-(27) in the article should be amended as shown below:

$$
\begin{gathered}
A^{*}=-\frac{K_{3,0}^{2}}{K_{2}^{2}} \\
H(T)-H\left(T_{0}\right)=\Delta H_{\mathrm{N}_{\mathrm{TB}}-\mathrm{N}}+\int_{T_{0}}^{T} \Delta C_{\mathrm{p}} \mathrm{d} T \\
\Delta S_{\mathrm{N}_{\mathrm{TB}}-\mathrm{N}}=-\left[\frac{\partial(\Delta f)}{\partial T}\right]_{T=T_{1}}=-\frac{3 K_{3,0} K_{2}^{\text {eff }}}{8 E}
\end{gathered}
$$

The Royal Society of Chemistry apologises for these errors and any consequent inconvenience to authors and readers.

\footnotetext{
${ }^{a}$ Grup de Propietats Físiques dels Materials (GRPFM-GCMM), Departament de Física, E.T.S.E.I.B, Universitat Politècnica de Catalunya, Diagonal, 647 08028 Barcelona, Spain. E-mail: David.orencio.lopez@upc.edu

${ }^{b}$ Departamento de Física Aplicada II, Facultad de Ciencia y Tecnología, Universidad del País Vasco, Apartado 644, E-48080 Bilbao, Spain

${ }^{c}$ Institute for Experimental Physics, Otto-von-Guerike Universität Magdeburg, ANP, Universitätsplatz, 39106 Magdeburg, Germany

${ }^{d}$ School of Physics and Astronomy, University of Manchester, Manchester M13 9PL, UK

${ }^{e}$ Chemistry, University of Southampton, Highfield, Southampton, SO17 1BJ, UK
} 